Article

\title{
A Parameter Identification Method for Stewart Manipulator Based on Wavelet Transform
}

\author{
Chenyang Zhang \\ School of Mechatronics Engineering, Harbin Institute of Technology, West Dazhi Street No.92, \\ Harbin 150000, China; zhangcy@126.com
}

Received: 21 January 2020; Accepted: 12 February 2020; Published: 15 February 2020

check for updates

\begin{abstract}
Aiming at inertial and viscous parameter identification for the Stewart manipulator regardless of the influence of Coulomb friction, a simple and effective dynamical parameter identification method based on wavelet transform and joint velocity analysis is proposed in this paper. Compared with previously known identification methods, the advantages of the new approach are that (1) the excitation trajectory is easy to design, and (2) it can not only identify the inertial matrix, but also the viscous matrix accurately regardless of the influence of Coulomb friction. Comparison is made among the identification method proposed in this paper, another identification method proposed previously, and the true value calculated with a formula. The errors from results of different identification methods demonstrate that the method proposed in this paper shows great adaptability and accuracy.
\end{abstract}

Keywords: parameter identification; wavelet transform; Coulomb friction and viscous friction model; dynamics; parallel manipulator; joint velocity analysis

\section{Introduction}

Parallel manipulators are becoming more and more interesting in the field of machine tools and robots due to their precision, stiffness, and dynamics [1-5]. Since parallel manipulators have a stiffness that can affect their dynamic characteristics, the modal space control algorithm has a good effect on solving the coupling of motion [6]. The multi-input multi-output system of the manipulator can be transformed into a set of single-input single-output systems along the modal direction by using modal space coordinate transformation. However, it requires not only the precise inertial parameters but also friction parameters to provide good performance [7]. So, identification of the dynamic parameters of the Stewart manipulator is one of the most important issues in high-performance motion control. However, few papers can be found in this area, due to the limited workspace and complex dynamic equations. Angela and Viola proposed a methodology for the parametric identification of the analytic dynamic model of a three degree of freedom delta-type parallel robot, which employed the recursive least squares identification algorithm [8]. Laboratory experiments for identification of the inertial parameters of cable-driven parallel robots were performed by Tempel et al. [9]. For the Stewart manipulator, Koekebakker proposed a method to identify by extracting the first-order coefficients of Fourier transform after six degrees of freedom exciting respectively, but this method did not take the phase lag caused by viscous friction into consideration, which had a relatively big influence on the identification [10]. Tian et al. improved the method above by solving the coefficient equations of Fourier transform [11], but it is important to note that this method can not accurately identify the viscous parameters influenced by Coulomb friction; at the same time, relative high-frequency motion is needed in this method. The identification method of structural parameters based on wavelet transform was widely used in the identification of time-varying or time-invariant structural dynamics because of its good identification accuracy and simple identification process [12-14]. Naerum et al. identified the 
linear part of a friction model with wavelet transform [15]. Wavelet-based neural network (WNN) with its inherent learning ability was used to solve the inverse kinematic problem and approximate the paths of mid and upper plates in circle and spiral trajectories of a specific class of serial-parallel manipulators, which are known as 2(6-UPU) manipulators [16]. Wavelet neural network was also widely used in the modeling of complex systems $[17,18]$. To discard the disadvantages of the identification method proposed by Tian, a new parameter identification method for the Stewart manipulator is proposed in this paper. The paper is organized as follows. In Section 2, the complete dynamic model of the Stewart manipulator is concisely surveyed, which sets up the terminology and notation used throughout the paper. The disadvantages of the identification method proposed by Tian are also explained in this section. The new identification theory based on wavelet transform is presented in Sections 3 and 4 alongside the specific identification process. In Section 5, the identification method proposed in this paper is verified using a simulated hydraulically driven Stewart manipulator. Finally, we present our conclusions.

\section{Dynamic Model of Stewart Manipulator and Analysis of the Identification Method Based on Fourier Transform}

\subsection{Dynamic Model of Stewart Manipulator}

Figure 1 shows the schematic of the Stewart manipulator. In this manipulator, the spatial motion of the moving platform is generated by six piston actuators. Each piston actuator consists of two parts connected with a gimbal joint where Coulomb friction and viscous friction exist. The manipulator has a total of six degrees of freedom, including three degrees of freedom of motion and three degrees of freedom of rotation around the axis. The equations of motion of Stewart manipulator are derived using Kane's method [11,19] and are written as:

$$
M_{t}(q) \ddot{q}+C_{t}(\dot{q}, q) \dot{q}+B_{t}(q) \dot{q}+G_{t}(q)=J_{l q}{ }^{T} f_{a}
$$

where $M_{t}, C_{t}$, and $B_{t}$ are the inertial parameter matrix, the Coriolis force parameter matrix, the viscous parameter matrix, and the gravity parameter matrix, $J_{l q}^{T}$ is the transpose matrix of $J_{l q}, J_{l q}$ is the Jacobin matrix between the work space and the leg, $f_{a}$ is the output force of the piston actuator, and $q$ is the six generalized vector of the platform, where $q=\left[\begin{array}{llllll}x & y & z & r x & r y & r z\end{array}\right]$.

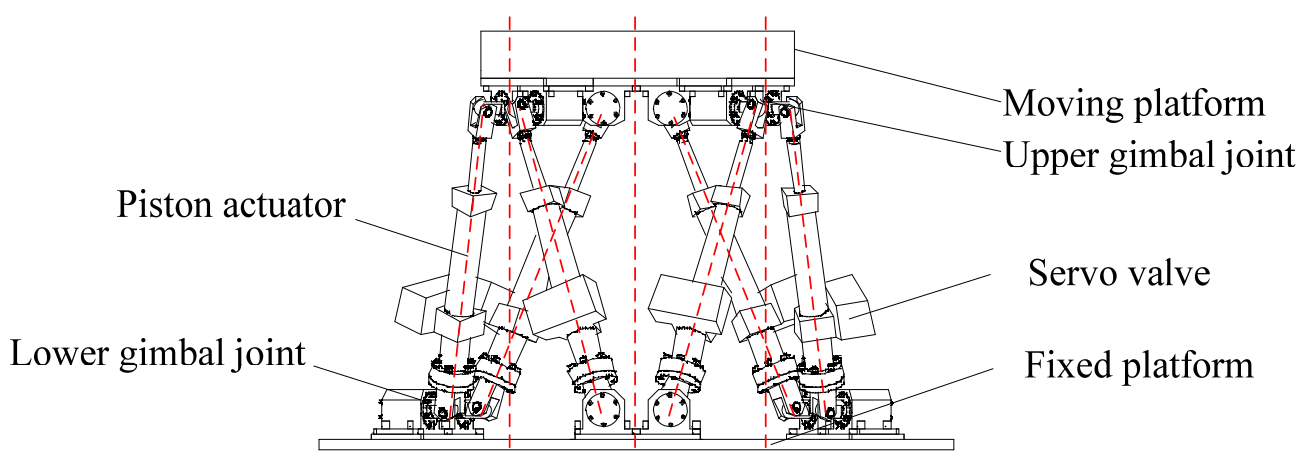

Figure 1. Schematic diagram of the Stewart manipulator.

In order to reduce the independent variables and to identify the parameters easily, the movement of the platform is limited to a small range of motion; thus, the dynamic model of the Stewart manipulator can be expressed as:

$$
M_{t} \ddot{q}+C_{t} \dot{q}+B_{t} \dot{q}+G_{t}=J_{l q}^{T} f_{a} .
$$

Although many friction models have been proposed to date, these friction models tend to be in the same form of friction when the system tends to steady movement, that is, the Coulomb friction 
and viscous friction model; so, the Coulomb friction and viscous friction model is of engineering significance, which is expressed as:

$$
Q_{f_{j}}=F_{c j} \operatorname{sign}\left(\dot{q}_{j}\right)+F_{v j} \dot{q}_{j}
$$

where $Q_{f_{j}}$ is the friction force or torque of joint $j$ and $\dot{q}_{j}$ is the corresponding velocity. Thus, the Coulomb friction matrix of the manipulator, which can be treated as derivation of the viscous matrix, can be expressed as:

$$
F_{c j}=\sum_{i=1}^{6}\left(\begin{array}{c}
J_{d i 1, q}^{T} f_{d 1 i} \operatorname{sign}\left(J_{d i 1, q} \dot{q}\right)+J_{d i 2, q}^{T} f_{d 2 i} \operatorname{sign}\left(J_{d i 2, q} \dot{q}\right) \\
+J_{u i 1, q}^{T} f_{u 1 i} \operatorname{sign}\left(J_{u i 1, q} \dot{q}\right) \\
+J_{u i 2, q}^{T} f_{u 2 i} \operatorname{sign}\left(J_{u i 2, q} \dot{q}\right)+J_{r i, q}^{T} f_{r i} \operatorname{sign}\left(J_{r i, q} \dot{q}\right)
\end{array}\right)
$$

where $f_{d 1 i}, f_{d 2 i}, f_{u 1 i}, f_{u 2 i}$, and $f_{r i}$ represent the Coulomb friction coefficients of the upper gimbal joints, the lower gimbal joints, and the revolute pair of the hydraulic leg around the center line of the actuator, while $J_{d i 1, q}, J_{d i 2, q}, J_{u i 1, q}, J_{u i 2, q}$, and $J_{r i, q}$ are the Jacobin matrix between the velocity of the joints and the work space. So, the dynamic model of the Stewart manipulator with Coulomb friction is:

$$
M_{t} \ddot{q}+C_{t} \dot{q}+B_{t} \dot{q}+G_{t}+F_{c j}=J_{l q}^{T} f_{a} .
$$

In general, the Coriolis force is quite small, so usually, the complete dynamic equation of the Stewart manipulator is:

$$
M_{t} \ddot{q}+B_{t} \dot{q}+G_{t}+F_{c j}=J_{l q}^{T} f_{a r}
$$

which is useful next.

\subsection{Analysis of the Identification Method Based on Fourier Transform}

The method based on Fourier transform is proposed by Tian et al. [11] by solving the coefficient equations of Fourier transform. For identification of the inertial parameters, this method has high accuracy, and the identification process is simple and effective. However, this method cannot accurately identify the viscous parameters when Coulomb friction exists in the joints of the manipulator. The specific reasons are as follows. First, in order to minimize the effect of Coulomb friction, inertial force is usually required as the integral part of the load force, so the portion of viscous force in the load force is reduced a lot. Therefore, in order to identify the viscous parameters, the frequency of the exciting trajectory should be reduced. However, this will affect the identification accuracy of the inertial parameters. Secondly, if the manipulator moves with low frequency, the effect of Coulomb friction on the identification of the inertial and viscous parameters is not considered in this method. Since sine or sinusoidal-like exciting trajectories are adopted in the identification, the velocities of the joints also should be sinusoidal or sinusoidal-like. As a consequence, the Coulomb friction force appears as a square wave, and the frequency is the same as that of the exciting trajectories. Since a square wave can be transformed as the superposition of multiple odd sine waves [11], if the excitating frequency of the manipulator is reduced, the Coulomb friction force will greatly change the first-harmonic coefficients obtained by Fourier transform, which will inevitably influence the identification results. Therefore, the identification method proposed by Tian has certain requirements on the frequency for accurate results. If the Coulomb friction force, viscous force, and inertial force of the manipulator are close in order, or the manipulator cannot achieve high-frequency motion, the accuracy of the identification can not be guaranteed. However, by restricting the motion range of the Stewart manipulator, the dynamic equations of the Stewart manipulator can be treated as constant linear equations, which help the identification a lot. Therefore, the influence of Coulomb friction should be eliminated in the new identification method. Based on the considerations above, the identification method with a wavelet function as the integral function and joint velocity analysis is proposed. 


\section{Identification Theory Based on Wavelet Transform}

The continuous wavelet transform of function $f(t)$ can be defined as:

$$
W_{\psi} f(t)_{a, b}=\frac{1}{\sqrt{a}} \int_{-\infty}^{+\infty} f(t) \psi\left(\frac{t-b}{a}\right) d t
$$

where $a>0$ and $b$ are the scale (or dilation) parameter and the shift (or translation) parameter, respectively. The function $\psi(t)$ is the mother wavelet function. The notation $W_{\psi} f(t)_{a, b}$ states that the function $f(t)$ is mapped to a function on the $(a, b)$ plane by the wavelet transform with the mother wavelet function $\psi(t)$. In this work, the analyzing wavelet is supposed to satisfy the following conditions:

1. The analyzing wavelet has a fast decay and vanishes at infinity,

2. It also has the first-order integral $\psi_{1}(t)$, which vanishes at infinity, as:

$$
\psi( \pm \infty)=\psi_{1}( \pm \infty)
$$

3. The analyzing wavelet has at least one vanishing moments, as:

$$
\int_{-\infty}^{+\infty} t^{i} \psi(t) d t=0, i=0,1
$$

Assuming that the first-order integral $f_{1}(t)$ of the function $f(t)$ exists, with the conditions above, the following result can be obtained by using partial integration:

$$
W_{\psi} f_{1}(t)_{a, b}=-a W_{\psi_{1}} f(t)_{a, b}
$$

where $W_{\psi} f_{1}(t)_{a, b}$ represents the wavelet transform of the first integral of $f(t)$. This algorithm presented in this section has been originally proposed by Sone et al. [20].

Normally, when the motion amplitude of the manipulator is sufficiently small, the matrix in Equation (4) can be considered as constant. Therefore, when sine or sinusoidal-like trajectories are applied as the trajectory, the Coulomb friction force in the load will be in the form of a ladder-like wave, and a ladder-like wave will appear downward or upward as the velocity directions of active or passive joints change. When the velocity directions of all joints change at the same time, the ladder-like wave will become a square wave. A new concept is brought out where if there is a time interval at which the velocity directions of all joints remain unchanged, this time interval could be called the constant direction space. For the Stewart manipulator, this space is relatively easy to be obtained when sine or sinusoidal-like trajectories with sufficiently small amplitudes (relatively small but reasonable) and identical frequencies are applied.

Although the wavelet transform of the constant is zero in the $(-\infty,+\infty)$ interval, when selecting the appropriate scale (or dilation) parameter $a$ and shift (or translation) parameter $b$, the wavelet transform of the constant can be quickly integrated to almost zero in a limited and relatively small time interval. So, when wavelet transform is performed in a constant direction space on both sides of Equation (6), an elimination effect on the Coulomb friction matrix and gravity matrix - which can be treated as a constant-will appear, and the time-varying term will be left. Thus, Coulomb friction and gravity will disappear; after wavelet transform is performed, only the inertial term and viscous term are left on both sides of the dynamic equations. Then, the dynamic equations of the Stewart manipulator can be transformed into algebraic equations, which are expressed as:

$$
\left[\begin{array}{ll}
M_{t} & B_{t}
\end{array}\right]\left[\begin{array}{c}
W_{\psi} \ddot{x} \\
-a W_{\psi_{1}} \ddot{x}
\end{array}\right]=W_{\psi} J_{l q}^{T} f_{a} .
$$


So, the inertial and viscous parameters of the manipulator can be easily and conveniently obtained by solving equations. In order to improve the accuracy of the identification, proper (usually not big) acceleration is usually needed. In this case, the tracking characteristics of the manipulator are often perfect; besides, the movement cycle will be quite stable, so there will be enough stable time intervals in which the velocity directions of all joints do not change.

\section{Identification Process}

The analysis of the identification method above based on wavelet transform and joint velocity analysis provides a solid foundation for a novel identification process. The steps of the identification method can be summarized as shown in Figure 2.

- Calculate the Jacobin matrix and design the reasonable trajectories. In order to create the constant direction space, the Jacobin matrix of the Stewart manipulator should be guaranteed first, and the reasonable trajectories based on the Jacobin matrix should be designed later.

- Excite the manipulator and save the data. Based on the trajectories designed previously, the manipulator is driven, and the related data are saved.

- Construct algebraic equations and equations solved. Based on wavelet transform, the algebraic equations related to the dynamic equations of the manipulator are obtained, and the inertial and viscous parameters can be calculated using the least square method.

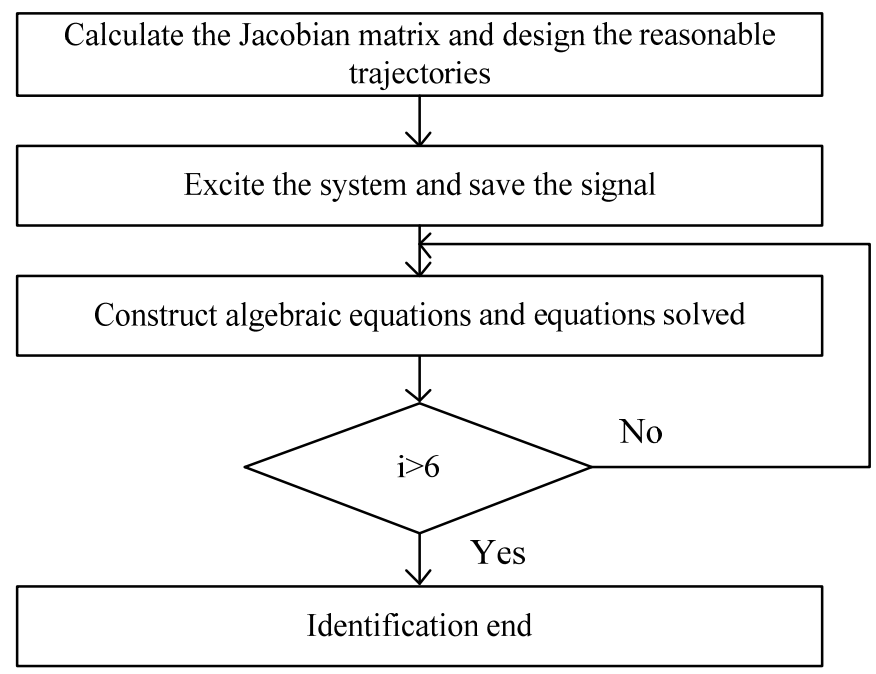

Figure 2. The flowchart of the identification method based on wavelet transform.

\section{Simulation and Comparison}

The simulation shown in Figure 3 of the identification method proposed in this paper is verified by using MATLAB software, in which the Stewart manipulator and the corresponding control part are built through the Simulink block. The identification algorithm is written according to the above identification process.

This model consists of five blocks on the top level. The first is the Signal Generator block, which can generate excitation trajectories as designed. The second is the Inverse Motion block, which is used to calculate the actuators' commands with respect to the trajectories. The third is the Hydraulic System block, including a simple PID controller and hydraulic actuator model. The fourth is the Plant block, representing the equations of the Stewart manipulator built using SimMechanics. The fifth is the Forward Solution block, which is used to compute the platform positions from the measured actuator lengths in real time. The calculation algorithm in the second and fifth block can be found in [10]. The configuration parameters of the Simulink ${ }^{\circledR}$ Model are shown in Table 1. 


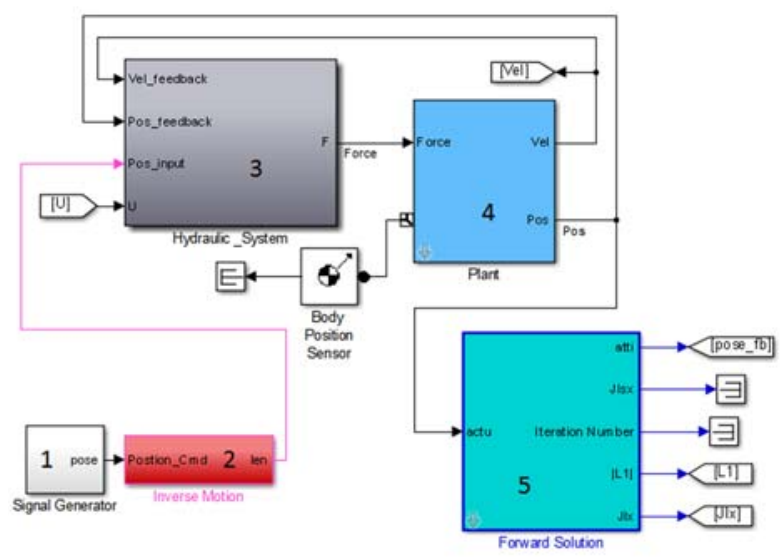

Figure 3. The simulink ${ }^{\circledR}$ Model of the Stewart manipulator.

Table 1. Configuration parameters of the Simulink ${ }^{\circledR}$ model.

\begin{tabular}{cc}
\hline Descriptions & Value \\
\hline Distribution radius of upper joint points $(\mathrm{m})$ & 2.1148 \\
Distribution radius of lower joint points $(\mathrm{m})$ & 2.5170 \\
Platform height in neutral position $(\mathrm{m})$ & 2.6519 \\
Half of the distributing angle for the upper joints(rad) & 0.0541 \\
Half of the distributing angle for the lower joints(rad) & 0.0454 \\
The length of hydraulic actuator $(\mathrm{m})$ & 3.41 \\
\hline
\end{tabular}

The nominal dynamic parameters used in the Simulink ${ }^{\circledR}$ model considering the actuators' inertial effects are shown in Table 2.

Table 2. Nominal dynamic parameters of the Simulink ${ }^{\circledR}$ model.

$\begin{array}{cc}\text { Descriptions } & \text { Value } \\ \text { Mass of the moving platform }(\mathrm{kg}) & 13,642 \\ \text { Inertia of the moving platform }\left(\mathrm{kg} \cdot \mathrm{m}^{2}\right) & 46,477.100 \\ \text { Inertia of the moving platform }\left(\mathrm{kg} \cdot \mathrm{m}^{2}\right) & 49,396.100 \\ \text { Inertia of the moving platform }\left(\mathrm{kg} \cdot \mathrm{m}^{2}\right) & 53,865.000 \\ \text { Inertia of actuator upper part around the gimbal point }\left(\mathrm{kg} \cdot \mathrm{m}^{2}\right) & 0.3085 \\ \text { Inertia of actuator lower part around the gimbal point }\left(\mathrm{kg} \cdot \mathrm{m}^{2}\right) & 0.2141 \\ \text { Mass of the actuator upper part }(\mathrm{kg}) & 152.6931 \\ \text { Mass of the actuator lower part }(\mathrm{kg}) & 16.1291 \\ \text { Height of the moving platform }(\mathrm{m}) & 0.9930 \\ \text { Mass center position of the actuator upper part relative to the upper gimbal point }(\mathrm{m}) & 0.9930 \\ \text { Mass center position of the actuator lower part relative to the lower gimbal point }(\mathrm{m}) & \end{array}$

Comparisons are made between the method proposed by Tian and the method proposed in this paper, which are named Method A and Method B, respectively. In order to verify the accuracy of the identification Method A, the friction model in the Simulink ${ }^{\circledR}$ model is first set to the viscous friction model; the viscous coefficient is set to $5000 \mathrm{~N} / \mathrm{m} \mathrm{s}$, and a sine position signal with frequency of 0.5 $\mathrm{Hz}$ is selected as the exciting trajectory. The identification results are shown in Table 3, where $\varepsilon$ is the relative absolute error.

It can be clearly seen from the identification results that the method proposed by Tian can accurately identify the inertial parameters and the viscous parameters of the manipulator, with the maximum identification error being $4.5 \%$. However, if Coulomb friction is added to the joints of the manipulator, the accuracy will be significantly reduced, while the identification method proposed in this paper with wavelet transform can still produce excellent results; the identification results of these two methods with $5 \mathrm{~N}$ Coulomb friction added to each joint are shown in Tables 4 and 5. 
Table 3. Identification results with viscous friction models and identification methods based on Fourier transform.

\begin{tabular}{|c|c|c|c|c|c|c|c|}
\hline \multirow{2}{*}{$\begin{array}{c}\text { Inertial } \\
\text { Parameters }\end{array}$} & \multicolumn{2}{|c|}{ Method A } & \multirow{2}{*}{$\begin{array}{l}\text { Nominal } \\
\text { Value }\end{array}$} & \multirow[b]{2}{*}{ Viscous Parameters } & \multicolumn{2}{|c|}{ Method A } & \multirow{2}{*}{$\begin{array}{c}\text { Nominal } \\
\text { Value }\end{array}$} \\
\hline & $\begin{array}{l}\text { Identified } \\
\text { Values }\end{array}$ & $\varepsilon(\%)$ & & & $\begin{array}{l}\text { Identified } \\
\text { Values }\end{array}$ & $\varepsilon(\%)$ & \\
\hline$M_{t}(1,1)(\mathrm{kg})$ & 14,255 & 0.1 & 14,224 & $B_{t}(1,1)\left(\mathrm{N} \cdot \mathrm{s} \cdot \mathrm{m}^{-1}\right)$ & 4134 & 0.2 & 4140.4 \\
\hline$M_{t}(2,2)(\mathrm{kg})$ & 14,255 & 0.1 & 14,224 & $B_{t}(2,2)\left(\mathrm{N} \cdot \mathrm{s} \cdot \mathrm{m}^{-1}\right)$ & 4134 & 0.2 & 4140.4 \\
\hline$M_{t}(3,3)(\mathrm{kg})$ & 14,409 & 0.1 & 14,393 & $B_{t}(3,3)\left(\mathrm{N} \cdot \mathrm{s} \cdot \mathrm{m}^{-1}\right)$ & 2034 & 0.3 & 2039.2 \\
\hline$M_{t}(4,4)\left(\mathrm{kg} \cdot \mathrm{m}^{2}\right)$ & 50,325 & 0.1 & 50,214 & $B_{t}(4,4)\left(\mathrm{N} \cdot \mathrm{m} \cdot \mathrm{s} \cdot \mathrm{rad}^{-1}\right)$ & 59,492 & 0.1 & $59,507.6$ \\
\hline$M_{t}(5,5)\left(\mathrm{kg} \cdot \mathrm{m}^{2}\right)$ & 53,244 & 0.1 & 53,133 & $B_{t}(5,5)\left(\mathrm{N} \cdot \mathrm{m} \cdot \mathrm{s} \cdot \mathrm{rad}^{-1}\right)$ & 59,494 & 0.1 & $59,507.6$ \\
\hline$M_{t}(6,6)\left(\mathrm{kg} \cdot \mathrm{m}^{2}\right)$ & 56,879 & 0.1 & 56,768 & $B_{t}(6,6)\left(\mathrm{N} \cdot \mathrm{m} \cdot \mathrm{s} \cdot \mathrm{rad}^{-1}\right)$ & 19,579 & 0.1 & $19,591.8$ \\
\hline$M_{t}(1,5)\left(\mathrm{N} \cdot \mathrm{s}^{2} \cdot \mathrm{rad}^{-1}\right)$ & 1145 & 4.5 & 1096 & $B_{t}(1,5)\left(\mathrm{N} \cdot \mathrm{s} \cdot \mathrm{rad}^{-1}\right)$ & 13,369 & 0.1 & 13,375 \\
\hline$M_{t}(2,4)\left(\mathrm{N} \cdot \mathrm{s}^{2} \cdot \mathrm{rad}^{-1}\right)$ & -1145 & 4.5 & -1096 & $B_{t}(2,4)\left(\mathrm{N} \cdot \mathrm{s} \cdot \mathrm{rad}^{-1}\right)$ & $-13,372$ & 0.1 & $-13,375$ \\
\hline$M_{t}(4,2)\left(\mathrm{N} \cdot \mathrm{s}^{2}\right)$ & -1145 & 4.5 & -1096 & $B_{t}(4,2)(\mathrm{N} \cdot \mathrm{s})$ & $-13,372$ & 0.1 & $-13,375$ \\
\hline$M_{t}(5,1)\left(\mathrm{N} \cdot \mathrm{s}^{2}\right)$ & 1145 & 4.5 & 1096 & $B_{t}(5,1)(\mathrm{N} \cdot \mathrm{s})$ & 13,369 & 0.1 & 13,375 \\
\hline
\end{tabular}

Table 4. Identification results of the inertial parameters of the Simulink ${ }^{\circledR}$ model with $5 \mathrm{~N}$ Coulomb friction.

\begin{tabular}{cccccc}
\hline & \multicolumn{2}{c}{ Method A } & \multicolumn{2}{c}{ Method B } & \\
\cline { 2 - 4 } Inertial Parameters & $\begin{array}{c}\text { Identified } \\
\text { Values }\end{array}$ & $\varepsilon$ (\%) & $\begin{array}{c}\text { Identified } \\
\text { Values }\end{array}$ & $\varepsilon$ (\%) & \\
\hline$M_{t}(1,1)(\mathrm{kg})$ & 14,146 & 0.5 & 14,242 & 0.1 & 14,224 \\
$M_{t}(2,2)(\mathrm{kg})$ & 14,125 & 0.7 & 14,256 & 0.2 & 14,224 \\
$M_{t}(3,3)(\mathrm{kg})$ & 14,410 & 0.1 & 14,400 & 0.1 & 14,393 \\
$M_{t}(4,4)\left(\mathrm{kg} \cdot \mathrm{m}^{2}\right)$ & 50,531 & 0.6 & 50,256 & 0.1 & 50,214 \\
$M_{t}(5,5)\left(\mathrm{kg} \cdot \mathrm{m}^{2}\right)$ & 53,451 & 0.6 & 53,215 & 0.2 & 53,133 \\
$M_{t}(6,6)\left(\mathrm{kg} \cdot \mathrm{m}^{2}\right)$ & 56,897 & 0.2 & 57,091 & 0.6 & 56,768 \\
$M_{t}(1,5)\left(\mathrm{N} \cdot \mathrm{s}^{2} \cdot \mathrm{rad}^{-1}\right)$ & 1238 & 13.0 & 1103 & 0.6 & 1096 \\
$M_{t}(2,4)\left(\mathrm{N} \cdot \mathrm{s}^{2} \cdot \mathrm{rad}^{-1}\right)$ & -1249 & 14.0 & -1178 & 7.5 & -1096 \\
$M_{t}(4,2)\left(\mathrm{N} \cdot \mathrm{s}^{2}\right)$ & -872 & 20.4 & -1128 & 2.9 & -1096 \\
$M_{t}(5,1)\left(\mathrm{N} \cdot \mathrm{s}^{2}\right)$ & 892 & 18.6 & 1125 & 2.6 & 1096 \\
\hline
\end{tabular}

Table 5. Identification results of the viscous parameters of the Simulink ${ }^{\circledR}$ model with $5 \mathrm{~N}$ Coulomb friction.

\begin{tabular}{cccccc}
\hline & \multicolumn{2}{c}{ Method A } & Method B & Nominal Value \\
\cline { 2 - 5 } Viscous Parameters & $\begin{array}{c}\text { Identified } \\
\text { Values }\end{array}$ & $\varepsilon \mathbf{~ ( \% )}$ & $\begin{array}{c}\text { Identified } \\
\text { Values }\end{array}$ & $\mathcal{\varepsilon} \mathbf{( \% )}$ & Nonn \\
& 4148 & 0.2 & 3935 & 4.9 & 4140.4 \\
$B_{t}(1,1)\left(\mathrm{N} \cdot \mathrm{s} \cdot \mathrm{m}^{-1}\right)$ & 4165 & 0.6 & 4053 & 2.1 & 4140.4 \\
$B_{t}(2,2)\left(\mathrm{N} \cdot \mathrm{s} \cdot \mathrm{m}^{-1}\right)$ & 3478 & 70.6 & 2032 & 0.4 & 2039.2 \\
$B_{t}(3,3)\left(\mathrm{N} \cdot \mathrm{s} \cdot \mathrm{m}^{-1}\right)$ & 68,962 & 15.9 & 59,250 & 0.4 & $59,507.6$ \\
$B_{t}(4,4)\left(\mathrm{N} \cdot \mathrm{m} \cdot \mathrm{s} \cdot \mathrm{rad}^{-1}\right)$ & 68,561 & 15.2 & 59,364 & 0.2 & $59,507.6$ \\
$B_{t}(5,5)\left(\mathrm{N} \cdot \mathrm{m} \cdot \mathrm{s} \cdot \mathrm{rad}^{-1}\right)$ & 25,637 & 30.9 & 19,563 & 0.1 & $19,591.8$ \\
$B_{t}(6,6)\left(\mathrm{N} \cdot \mathrm{m} \cdot \mathrm{s} \cdot \mathrm{rad}^{-1}\right)$ & 15,801 & 18.1 & 13,603 & 1.7 & 13,375 \\
$B_{t}(1,5)\left(\mathrm{N} \cdot \mathrm{s} \cdot \mathrm{rad}^{-1}\right)$ & $-16,034$ & 19.9 & $-13,313$ & 0.5 & $-13,375$ \\
$B_{t}(2,4)\left(\mathrm{N} \cdot \mathrm{s} \cdot \mathrm{rad}^{-1}\right)$ & $-13,476$ & 0.8 & $-13,104$ & 2.0 & $-13,375$ \\
$B_{t}(4,2)(\mathrm{N} \cdot \mathrm{s})$ & 13,466 & 0.7 & 13,468 & 0.7 & 13,375 \\
$B_{t}(5,1)(\mathrm{N} \cdot \mathrm{s})$ & & & & \\
\hline
\end{tabular}

It can be seen that, as $5 \mathrm{~N}$ Coulomb friction is added to each joint, the inertial and viscous identification results of the identification method based on Fourier transform change, while the main diagonal parameters of the inertial matrix are still precise, with the maximum identification error being $0.7 \%$. However, the non-diagonal elements in the inertial matrix are inaccurate; at the same time, more elements in the viscous matrix are badly affected, with the maximum identification error being $70.6 \%$. Since $5 \mathrm{~N}$ is still relatively small to the load force, the method proposed by Tian et al. can be easily affected by Coulomb friction. The identification method with wavelet transform and velocity constant space has a much higher identification accuracy, which means that almost all the identification results are satisfied (the relative absolute error of most elements in the inertial matrix and the viscous matrix is less than $5 \%$ ). However, it shows a large error $(7 \%)$ in the inertial parameter 
matrix $\left(M_{t}(2,4)\right)$. This error is due to the condition number of the identification equation. However, according to the anti-symmetric property of the inertial matrix caused by the structure symmetry of the Stewart manipulator, more accurate values from another degree of freedom can be adopted as the result of the identification, which are obtained from an equation with a small condition number. When $30 \mathrm{~N}$ of Coulomb friction is added to each joint, the identification results of the method with wavelet transform are shown in Table 6.

Table 6. Identification results of parameters of the Simulink model with $30 \mathrm{~N}$ of Coulomb friction.

\begin{tabular}{|c|c|c|c|c|c|c|c|}
\hline \multirow[b]{2}{*}{ Inertial Parameters } & \multicolumn{2}{|c|}{ Method B } & \multirow[b]{2}{*}{$\begin{array}{l}\text { Nominal } \\
\text { Value }\end{array}$} & \multirow[b]{2}{*}{ Viscous Parameters } & \multicolumn{2}{|c|}{ Method B } & \multirow[b]{2}{*}{$\begin{array}{l}\text { Nominal } \\
\text { Value }\end{array}$} \\
\hline & $\begin{array}{c}\text { Identified } \\
\text { Values }\end{array}$ & $\varepsilon(\%)$ & & & $\begin{array}{c}\text { Identified } \\
\text { Values }\end{array}$ & $\varepsilon(\%)$ & \\
\hline$M_{t}(1,1)(\mathrm{kg})$ & 14,247 & 0.2 & 14,224 & $\mathrm{~B}_{\mathrm{t}}(1,1)\left(\mathrm{N} \cdot \mathrm{s} \cdot \mathrm{m}^{-1}\right)$ & 3949 & 4.6 & 4140.4 \\
\hline$M_{t}(2,2)(\mathrm{kg})$ & 14,251 & 0.2 & 14,224 & $\mathrm{~B}_{\mathrm{t}}(2,2)\left(\mathrm{N} \cdot \mathrm{s} \cdot \mathrm{m}^{-1}\right)$ & 4036 & 2.5 & 4140.4 \\
\hline$M_{t}(3,3)(k g)$ & 14,390 & 0.1 & 14,393 & $\mathrm{~B}_{\mathrm{t}}(3,3)\left(\mathrm{N} \cdot \mathrm{s} \cdot \mathrm{m}^{-1}\right)$ & 2030 & 0.5 & 2039.2 \\
\hline$M_{t}(4,4)\left(\mathrm{kg} \cdot \mathrm{m}^{2}\right)$ & 50,221 & 0.1 & 50,214 & $\mathrm{~B}_{\mathrm{t}}(4,4)\left(\mathrm{N} \cdot \mathrm{m} \cdot \mathrm{s} \cdot \mathrm{rad}^{-1}\right)$ & 59,399 & 0.2 & $59,507.6$ \\
\hline$M_{t}(5,5)\left(\mathrm{kg} \cdot \mathrm{m}^{2}\right)$ & 53,225 & 0.2 & 53,133 & $\mathrm{~B}_{\mathrm{t}}(5,5)\left(\mathrm{N} \cdot \mathrm{m} \cdot \mathrm{s} \cdot \mathrm{rad}^{-1}\right)$ & 59,387 & 0.2 & $59,507.6$ \\
\hline$M_{t}(6,6)\left(\mathrm{kg} \cdot \mathrm{m}^{2}\right)$ & 57,090 & 0.6 & 56,768 & $\mathrm{~B}_{\mathrm{t}}(6,6)\left(\mathrm{N} \cdot \mathrm{m} \cdot \mathrm{s} \cdot \mathrm{rad}^{-1}\right)$ & 19,561 & 0.2 & $19,591.8$ \\
\hline$M_{t}(1,5)\left(\mathrm{N} \cdot \mathrm{s}^{2} \cdot \mathrm{rad}^{-1}\right)$ & 1132 & 3.3 & 1096 & $\mathrm{~B}_{\mathrm{t}}(1,5)\left(\mathrm{N} \cdot \mathrm{s} \cdot \mathrm{rad}^{-1}\right)$ & 13,591 & 1.6 & 13,375 \\
\hline$M_{t}(2,4)\left(\mathrm{N} \cdot \mathrm{s}^{2} \cdot \mathrm{rad}^{-1}\right)$ & -1160 & 5.8 & -1096 & $\mathrm{~B}_{\mathrm{t}}(2,4)\left(\mathrm{N} \cdot \mathrm{s} \cdot \mathrm{rad}^{-1}\right)$ & 13,358 & 0.1 & $-13,375$ \\
\hline$M_{t}(4,2)\left(\mathrm{N} \cdot \mathrm{s}^{2}\right)$ & -1107 & 0.1 & -1096 & $\mathrm{~B}_{\mathrm{t}}(4,2)(\mathrm{N} \cdot \mathrm{s})$ & 13,120 & 1.9 & $-13,375$ \\
\hline$M_{t}(5,1)\left(\mathrm{N} \cdot \mathrm{s}^{2}\right)$ & 1126 & 2.7 & 1096 & $\mathrm{~B}_{\mathrm{t}}(5,1)(\mathrm{N} \cdot \mathrm{s})$ & 13,435 & 0.4 & 13,375 \\
\hline
\end{tabular}

A good result of the identification method with wavelet transform can still be achieved, with the maximum identification error being 5.8\%, which shows excellent adaptability. Therefore, this method is particularly suitable for a parallel manipulator with Coulomb friction, especially for the relatively sophisticated manipulators that cannot achieve high-frequency sine motion.

\section{Conclusions}

A very compact identification method is proposed in this paper, which can not only identify the inertial matrix but also accurately determine the viscous matrix, regardless of the influence of Coulomb friction. The dynamic differential equations of the Stewart manipulator can be transformed into algebraic equations with wavelet transform for the relationship between the Coulomb friction in the joints and the sine or sinusoidal-like exciting trajectories in the time interval, which is called the constant direction space. The inertial and viscous parameters can be solved by using the least square method. The proposed identification method is validated by the identification results of a simulated parallel manipulator in which Coulomb friction and the viscous friction model are added to joints, which shows excellent adaptability compared with the identification method proposed by Tian et al. Therefore, this method is particularly suitable for a parallel manipulator with Coulomb friction, especially for the relatively sophisticated manipulators that cannot achieve high-frequency sinusoidal motion.

Funding: This research received no external funding.

Conflicts of Interest: The author declares no conflict of interest.

\section{References}

1. Zi, B.; Sun, H.; Zhang, D. Design analysis and control of a winding hybrid-driven cable parallel manipulator. Robot Cim.-Int. Manuf. 2017, 48, 196-208. [CrossRef]

2. Gao, C.H.; Zheng, S.T.; Cong, D.C.; Han, J.W.; Yang, Z.D.; Sun, J.Y. Modeling and control of the cscec multi-function testing system. J. Earthq. Eng. 2018, 2, 257-280. [CrossRef]

3. Tao, H.; Qu, Z.Y.; Cong, D.C. Hybrid position / force control scheme for hydraulic parallel manipulator. Nongye Jixie Xuebao 2018, 49, 361-366. [CrossRef] 
4. Zhang, L.P.; Cong, D.C.; Yang, Z.D.; Zhang, Y.Y.; Han, J.W. Robust tracking and synchronization of double shaking tables based on adaptive sliding mode control with novel reaching law. 2016, 8686-8702. [CrossRef]

5. Gao, C.H.; Cong, D.C.; Liu, X.C.; Yang, Z.D.; Tao, H. Hybrid position/force control of 6-dof hydraulic parallel manipulator using force and vision. Ind. Robot 2016, 43, 274-283. [CrossRef]

6. Jiang, H.Z.; He, J.F.; Tong, Z.Z. Modal space control for a hydraulically driven Stewart platform. JCET 2012, 3, 106-115.

7. Tian, T.X.; Jiang, H.Z.; Huang, Q.T.; He, J.F.; Nie, B.X. Control strategy of modal space for a hydraulically-driven Stewart platform considering passive joint damping. Huanan Ligong Daxue Xuebao Ziran Kexueban 2015, 43, 56-62. [CrossRef]

8. Angel, L.; Viola, J. Parametric identification of a delta type parallel robot. In Proceedings of the 2016 IEEE Colombian Conference on Robotics and Automation (CCRA), Bogota, Colombia, 29-30 September 2016. [CrossRef]

9. Tempel, P.; Tempier, O.; Herve, P.E.; Gouttefarde, M.; Pott, A. Estimating inertial parameters of suspended cable-driven parallel robots-Use case on cogiro. In Proceedings of the IEEE International Conference on Robotics and Automation 2017, Singapore, 29 May 2017; pp. 6093-6098. [CrossRef]

10. Koekebakker, S.H. Model based control of a flight simulator motion system. Ph.D. Thesis, Delft University of Technology, Delft, The Netherlands, 2001.

11. Tian, T.X.; Jiang, H.Z.; Tong, Z.Z.; He, J.F.; Huang, Q.T. An inertial parameter identification method of eliminating system damping effect for a six-degree-of-freedom parallel manipulator. Chin. J. Aeronaut 2015, 28, 582-592. [CrossRef]

12. Xu, X.; Shi, Z.Y.; You, Q. Identification of linear time-varying systems using a wavelet-based state-space method. Mch. Syst. Signal Pr. 2012, 26, 91-103. [CrossRef]

13. Shi, Z.Y.; Xu, X.; Law, S.S. Parameter identification of ltv dynamical system based on wavelet method. In Proceedings of the 4th International Conference on Earthquake Engineering, Taipei, Taiwan, 12-13 October 2006. [CrossRef]

14. Ghanem, R.; Romeo, F.A. Wavelet-based approach for the identification of linear time-varying dynamical systems. J. Sound Vib. 2012, 234, 555-576. [CrossRef]

15. Naerum, E.; Cornella, J.; Elle, J.O. Wavelet networks for estimation of coupled friction in robotic manipulators. In Proceedings of the IEEE International Conference on Robotics \& Automation, Pasadena, CA, USA, 19-23 May 2008; pp. 862-867. [CrossRef]

16. Rahmani, A.; Ghanbari, A.; Pedrammehr, S. Kinematic analysis for hybrid 2-(6-UPU) manipulator using wavelet neural network. Adv. Mater 2014, 1016, 726-730. [CrossRef]

17. Razali, N.; Pauline, O.; Ibrahim, M.; Wan, S.; Wan, D.; Zarita, Z. Modeling of acetosolv pulping of oil palm fronds using response surface methodology and wavelet neural networks. Cellulose 2019, 26, 4615-4628. [CrossRef]

18. Huang, L.; Wang, J. Forecasting energy fluctuation model by wavelet decomposition and stochastic recurrent wavelet neural network. Neurocomputing 2018, 309, 70-82. [CrossRef]

19. Tian, T.X.; Jiang, H.Z.; Tong, Z.Z.; He, J.F. Modal space decoupled optimal design for a class of symmetric spatial parallel mechanisms with consideration of passive joint damping. Robotica 2015, 33, 828-847. [CrossRef]

20. Sone, A.; Hata, H.; Masuda, A. Identification of structural parameters using the wavelet transform of acceleration measurements. J. Press. Vessel. Technol. 2004, 126, 128-133. [CrossRef]

(C) 2020 by the author. Licensee MDPI, Basel, Switzerland. This article is an open access article distributed under the terms and conditions of the Creative Commons Attribution (CC BY) license (http://creativecommons.org/licenses/by/4.0/). 